\title{
Besprechung von A. Levkowitz
}

A. Levkowitz will in einer ausführlichen Literaturübersicht: »Religiöse Denker der Gegenwart. Vom Wandel der modernen Lebensanschauung ${ }^{1}{ }^{1}$ solche jüdischen Leser, die infolge anderweitiger Beschäftigung keine Gelegenheit hatten, die Philosophie der Gegenwart aus den Quellen oder aus den üblichen Berichten in Tageszeitungen kennen zu lernen, mit dieser vertraut machen. Eine gewisse Primitivität der Argumentation und eine gewisse Wiederholung von längst Bekanntem ist daher unvermeidlich. Von dem festen Boden der Religion des Judentums aus kann der Verfasser die einzelnen Philosophen mühelos beurteilen. Er bemüht sich um eine "ernste und tiefe Auseinandersetzung mit den geistigen Kräften der Umwelt ", deren Ergebnis die Identifikation einer Synthese von Bergsonscher schöpferischer Entwicklung mit den Idealen der Cohenschen Menschheits-Ethik und dem Ottoschen Heiligen, die Identifikation dieser Synthese also mit der altjüdischen Weltanschauung ist. Nicht ohne Hartnäckigkeit weiß der Verfasser gegenüber den LebensPhilosophen die Ideale, gegenüber den Idealisten das Leben zu betonen.

Außer dem erwähnten unbewußten Zweck hat die Schrift noch den ausdrücklich vom Verfasser hervorgehobenen: Nehmend und gebend den (sic!) jüdischen Teil am religiösen Suchen unserer Zeit zu haben. Und zwar geht dieses Ringen um Teilnahme an der modernen Kultur nach der Ansicht des Verfassers auf den klassischen Universalismus des Judentums zurück.

1 Berlin, Philo-Verlag 1923. 